\title{
openheart The influence of system delay on 30-day and on long-term mortality in patients with anterior versus non-anterior ST-segment elevation myocardial infarction: a cohort study
}

Sonja Postma, ${ }^{1}$ Jan-Henk E Dambrink, ${ }^{2}$ A T Marcel Gosselink, ${ }^{2}$ Jan Paul Ottervanger, ${ }^{2}$ Evelien Kolkman, ${ }^{1}$ Jurrien M ten Berg, ${ }^{3}$ Harry Suryapranata, ${ }^{4}$ Arnoud W J van 't $\mathrm{Hof}^{2}$

To cite: Postma S,

Dambrink J-HE,

Gosselink ATM, et al. The influence of system delay on 30-day and on long-term mortality in patients with anterior versus non-anterior ST-segment elevation myocardial infarction: a cohort study. Open Heart 2015;2: 000201.

doi:10.1136/openhrt-2014000201

Received 29 September 2014 Revised 9 February 2015 Accepted 4 March 2015

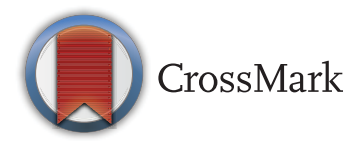

For numbered affiliations see end of article.

Correspondence to Dr A W J van "t Hof; v.r.c.derks@isala.nl

\section{ABSTRACT}

Aim: To evaluate the relationship between system delay and 30-day and long-term mortality in patients with anterior versus non-anterior ST-elevation myocardial infarction (STEMI).

Methods: We conducted a prospective observational cohort study. Patients with STEMI who were transported to the Isala Hospital, Zwolle, and underwent primary percutaneous coronary intervention (pPCl) from 2005 until 2010 were included. These patients were divided into quartiles of system delay (time from first medical contact until reperfusion therapy): Q1-Q4.

Results: In total, 3041 patients were included in our study. $41 \%(n=1253)$ of the patients had an anterior myocardial infarction (MI) and $59 \%$ of the patients $(n=1788)$ had a non-anterior MI. Only in patients with an anterior MI, prolonged system delay was associated with a higher mortality (30-day Q1: 2.6\%, Q2: 3.1\%, Q3: $6.8 \%$, Q $4: 7.4 \%, p=0.001$; long-term Q1: $12.8 \%$, Q2: 13.7\%, Q3: 24.1\%, Q4: 22.6\%, p<0.001). After multivariable adjustment, prolonged system delay was associated with a higher 30-day and long-term mortality in patients with an anterior MI (30 day Q2: HR 1.18, $95 \% \mathrm{Cl}$ (0.46 to 3.00), Q3: HR 2.45, 95\% Cl (1.07 to 5.63), Q4: HR 2.25, 95\% Cl (0.97 to 5.25)); long-term Q2: HR 1.09, 95\% Cl (0.71 to 1.68), Q3: HR 1.68, 95\% Cl (1.13 to 2.49), Q4: HR $1.55,95 \% \mathrm{Cl}(1.03$ to 2.33$)$ ), but not in patients with a non-anterior MI.

Conclusions: Prolonged system delay significantly increased short-term as well as long-term mortality in patients with an anterior MI. This effect was not demonstrated in patients with a non-anterior MI. Therefore, it is of the greatest importance to minimise system delay in patients who present with an anterior MI.

\section{INTRODUCTION}

As stated in the guidelines of the American College of Cardiology/American Heart Association (ACC/AHA) and of the European

\section{KEY MESSAGES}

What is already known about this subject? It is known that system delay is independently associated with mortality.

What does this study add?

We hypothesised that the effect of system delay on mortality would be most apparent in high-risk patients (patients with an anterior myocardial infarction) compared with low-risk patients (patients with a non-anterior myocardial infarction).

How might this impact on clinical practice? Focusing on system delay, especially in high-risk patients, may improve clinical practice since we have demonstrated that prolonged system delay significantly increased short-term as well as long-term mortality in high-risk patients. This effect was not demonstrated in low-risk patients.

Society of Cardiology (ESC), it is crucial to perform rapid reperfusion therapy in patients with ST-segment elevated myocardial infarction (STEMI), ${ }^{1}{ }^{2}$ because every minute of delay in these patients affects mortality. ${ }^{3}$ Therefore, currently time delays like system delay, patient delay, transportation delay, door-in-door-out time and door-to-balloon (D2B) time care are of great concern for patients with STEMI. ${ }^{4-8}$ System delay, defined as time from first medical contact (FMC, ie, EMS call) to reperfusion therapy, is a relatively new time delay which can be optimised by optimising the system. As demonstrated by Terkelsen et $a l^{4}{ }^{4}$ system delay was independently associated with mortality. Since we hypothesised that this effect would be the most apparent in high-risk patients, we have investigated the effect of system delay on 30-day and 
on long-term mortality in patients with an anterior myocardial infarction (MI) versus a non-anterior MI.

\section{METHODS AND ANALYSIS \\ Population}

All patients with consecutive STEMI, who were transported to our percutaneous coronary intervention (PCI) centre with the intention to perform primary PCI (pPCI), from 2005 until 2010, were prospectively registered in a dedicated database. Criteria for the diagnosis of STEMI were: (1) history of cardiac symptoms for at least $30 \mathrm{~min}$ in the last $12 \mathrm{~h}$ or between 12 and $24 \mathrm{~h}$ if they had persistent symptoms with evidence of ongoing ischaemia; (2) elevated levels of creatine kinase or creatine kinase-MB and (3) concurrent ECG changes: ST-segment elevation of $>0.1 \mathrm{mV}$ in at least two adjacent ECG leads. ${ }^{9}$

Infarct size was calculated as the peak level of creatine kinase (peak CK) within $24 \mathrm{~h}$ after admission. ${ }^{10}$ The municipal registration in the Netherlands was consulted for the mortality of all patients in this study.

The included population was divided into four groups according to the quartiles of system delay (Q1, Q2, Q3 and Q4). System delay was defined as the time from FMC, that is, EMS call to reperfusion therapy. Four other time intervals were also evaluated: (1) symptom onset (SO) diagnosis: time from $\mathrm{SO}$ to indication $\mathrm{MI}$ (time diagnostic ECG) either in the ambulance or at a spoke centre, (2) diagnosis door PCI: time from diagnosis to arrival at the PCI centre, (3) D2B: time from arrival at the PCI centre to balloon inflation (BI), and (4) total ischaemic time: time from SO to BI.

Patients were excluded if one of the following criteria was met: patients were walk-ins, they were not treated by PCI, D2B time was $>180 \mathrm{~min}$, system delay was unknown or mortality could not be retrieved.

\section{pPCI procedure}

The staff of the catheterisation laboratory of the PCI centre was preinformed about the estimated time of arrival of the patient and was activated well before the arrival of the patient. In case the staff lived more than 30 min away from the PCI centre, they had to stay in the PCI centre while being on-call. All patients were treated prehospital with an intravenous bolus of $5000 \mathrm{IU}$ of unfractionated heparin and $500 \mathrm{mg}$ aspirin intravenously. During the study period, the administration of clopidogrel on top of aspirin and heparin as prehospital treatment was implemented at 1 July 2006. The administration of GPIIBIIIA blockers in the prehospital phase was left to the discretion of the referring physicians.

The location of the acute vessel occlusion was determined in this study by the PCI operator. Consequently, two groups were made according to the location: left anterior descending artery (LAD; anterior MI) versus non-LAD (non-anterior MI).

\section{Statistical analysis}

Statistical analysis was performed with SPSS V.20.0. Continuous data were expressed as mean $\pm \mathrm{SD}$ or median and IQR. Categorical data were presented as percentages. A Kruskal-Wallis test was used for continuous data since these were non-Gaussian distributed. A Pearson's $\chi^{2}$ test was used for categorical data. The continuous variable infarct size was converted into a dichotomous variable by dividing the de-continuous variable in IQRs and defining the IQR $0.75-1.00$ as large enzymatic infarct size ( 75 th centile). A p for trend was calculated for large enzymatic infarct size, and for 30-day and longterm mortality between the quartiles of system delay.

To assess whether anterior MI might interfere with the relationship between system delay and 30-day and longterm mortality, interaction testing was performed.

Logistic regression analyses were performed to estimate the effect of system delay on large enzymatic infarct size. Variables included in the models were age, gender, smoking, diabetes mellitus (DM), hypertension, hypercholesterolaemia, previous MI, previous PCI, previous coronary artery bypass grafting (CABG), type of triage, ST deviation on diagnostic ECG and the quartiles of system delay. Cox regression analysis was performed to estimate the effect of system delay on 30-day and on long-term mortality. Variables included in the models for 30-day mortality were age, gender, DM, hypertension, type of triage, thrombolysis in myocardial infarction (TIMI) risk score and the quartiles of system delay. For the Cox regression analysis of long-term mortality the previous MI, previous PCI and previous CABG were added.

All the above described statistical tests were performed two sided. In all the statistical analyses, $\mathrm{p}$ values $<0.05$ were considered as statistically significant.

The study was conducted according to the principles of the Declaration of Helsinki and the protocol was approved by the local institutional review board. No extramural funding was used to support this work. The authors are fully responsible for the design and conduct of this study, all study analyses and drafting and editing of the paper.

\section{RESULTS}

From 2005 until 2010, 4655 patients were referred to our hospital with the intention to perform pPCI. In total, 312 patients $(7.7 \%)$ were walk-ins at the PCI centre; 668 patients did not undergo PCI (14.3\%); for 344 patients, the D2B time was $>180$ min $(7.4 \%)$; for 245 patients, system delay was unknown $(5.3 \%)$; and in the case of 45 patients $(1.0 \%)$, mortality could not be retrieved. Of the remaining 3041 patients, 41\% $(\mathrm{n}=1253)$ of the patients had an anterior MI and 59\% $(n=1788)$ had a non-anterior MI. There was a significant interaction effect between anterior infarction and the quartiles of system delay on 30-day $(\mathrm{p}=0.048)$ and on long-term mortality $(\mathrm{p}=0.027)$. Therefore, the results are presented separately for patients with an anterior MI and patients with a non-anterior MI. 


\section{Anterior MI}

The baseline characteristics are described in table 1 . Patients with a prolonged system delay were older, were less often triaged in the field and had less ST-deviation on the diagnostic ECG. Gender, DM and the TIMI risk score differed among the quartiles of system delay. The time intervals are illustrated in figure 1A. All time delays were significantly different between the quartiles of system delay. The median follow-up time was 5.3 (3.6-6.6) years. System delay was independently associated with a large enzymatic infarct size (Q2: OR $1.85,95 \%$ CI (1.19 to 2.86$)$, Q3: OR $1.80,95 \%$ CI $(1.15$ to 2.81$), \mathrm{Q} 4:$ OR $1.15,95 \%$ CI (0.72 to 1.84$))$. After Cox regression analysis, prolonged system delay was independently associated with 30-day mortality (Q2: HR 1.18, 95\% CI (0.46 to 3.00$)$, Q3: HR 2.45, $95 \%$ CI (1.07 to 5.63), Q4: HR 2.25, 95\% CI $(0.97$ to 5.25$))$ and with long-term mortality (Q2: HR $1.09,95 \%$ CI $(0.71$ to 1.68), Q3: HR 1.68, 95\% CI (1.13 to 2.49), Q4: HR 1.55, $95 \%$ CI (1.03 to 2.33$)$ ) (figure $2 \mathrm{~A}$ ).

Table 1 Baseline characteristics

\begin{tabular}{|c|c|c|c|c|c|}
\hline $\begin{array}{l}\text { System delay in quartiles } \\
\text { (min) }\end{array}$ & $\begin{array}{l}\text { Q1: } 72.0 \\
(62.0-78.0)\end{array}$ & $\begin{array}{l}\text { Q2: } 92.0 \\
(87.0-97.0)\end{array}$ & $\begin{array}{l}\text { Q3: } 114.0 \\
(108.0-121.0)\end{array}$ & $\begin{array}{l}\text { Q4: } 160.0 \\
(142.0-190.0)\end{array}$ & $\begin{array}{l}\text { p } \\
\text { Value }\end{array}$ \\
\hline \multicolumn{6}{|l|}{ Characteristic } \\
\hline Anterior $\mathrm{MI}$ & $(n=313)$ & $(n=321)$ & $(n=323)$ & $(n=296)$ & \\
\hline Age years (mean $\pm S D)$ & $62.6 \pm 12.5(n=313)$ & $62.2 \pm 12.7(n=321)$ & $65.8 \pm 12.6(n=323)$ & $64.5 \pm 13.2(n=296)$ & 0.001 \\
\hline Male gender & $247 / 313(78.9 \%)$ & $241 / 321(75.1 \%)$ & $218 / 323(67.5 \%)$ & $218 / 296(73.6 \%)$ & 0.011 \\
\hline Previous MI & $20 / 312(6.4 \%)$ & $27 / 321(8.4 \%)$ & $34 / 323(10.5 \%)$ & $32 / 296(10.8 \%)$ & 0.189 \\
\hline Previous CABG & $3 / 313(1.0 \%)$ & $4 / 321(1.2 \%)$ & $6 / 323(1.9 \%)$ & $3 / 296(1.0 \%)$ & 0.734 \\
\hline Previous $\mathrm{PCl}$ & $22 / 313(7.0 \%)$ & $24 / 321(7.5 \%)$ & $23 / 321(7.2 \%)$ & 32/296 (10.8\%) & 0.266 \\
\hline Hypertension & $107 / 313(34.2 \%)$ & $88 / 320(27.5 \%)$ & $112 / 320(35.0 \%)$ & $108 / 295(36.6 \%)$ & 0.077 \\
\hline DM & $25 / 313(8.0 \%)$ & $31 / 321(9.7 \%)$ & $50 / 323(15.5 \%)$ & $28 / 296(9.5 \%)$ & 0.012 \\
\hline Hypercholesterolemia & $50 / 311(16.1 \%)$ & $53 / 319(16.6 \%)$ & $62 / 321(19.3 \%)$ & $67 / 294(22.8 \%)$ & 0.130 \\
\hline Smoking & $124 / 312(39.7 \%)$ & $134 / 319(42.0 \%)$ & $111 / 317(35.0 \%)$ & 116/295 (39.3\%) & 0.332 \\
\hline Killip class $>1$ & 292/313 (93.3\%) & 299/321 (93.1\%) & $300 / 323$ (92.9\%) & 265/294 (90.1\%) & 0.413 \\
\hline TIMI risk score & $3.24 \pm 2.12$ & $3.22 \pm 2.07$ & $3.56 \pm 2.09$ & $3.82 \pm 2.30$ & $<0.001$ \\
\hline (mean $\pm S D$, median $(I Q R))$ & $\begin{array}{l}3.0(1.0-4.0) \\
(n=311)\end{array}$ & $\begin{array}{l}3.0(1.0-5.0) \\
(n=321)\end{array}$ & $\begin{array}{l}2.0(3.0-5.0) \\
(n=323)\end{array}$ & $\begin{array}{l}4.0(2.0-5.0) \\
(n=294)\end{array}$ & \\
\hline Field triage & 269/313 (85.9\%) & 239/321 (74.5\%) & 196/323 (60.7\%) & $134 / 296(45.3 \%)$ & $<0.001$ \\
\hline GPIIBIIIA blocker* & $82 / 263(31.2 \%)$ & 92/275 (33.5\%) & 99/283 (35.0\%) & 99/249 (39.8\%) & 0.217 \\
\hline \multirow{2}{*}{$\begin{array}{l}\text { ST-segment deviation } \\
\text { (diagnostic ECG) }\end{array}$} & $13.48 \pm 8.76$ & $12.51 \pm 7.87$ & $12.51 \pm 8.41$ & $11.45 \pm 10.53$ & 0.001 \\
\hline & $\begin{array}{l}11.0(8.0-17.0) \\
(n=201)\end{array}$ & $\begin{array}{l}11.0(7.0-16.0) \\
(n=216)\end{array}$ & $\begin{array}{l}11.0(7.0-16.0) \\
(n=227)\end{array}$ & $\begin{array}{l}8.0(5.0-15.0) \\
(n=220)\end{array}$ & \\
\hline Multivessel disease & $130 / 313(41.5 \%)$ & $142 / 320(44.4 \%)$ & $137 / 322(42.5 \%)$ & $119 / 295$ (40.3\%) & 0.774 \\
\hline Non-anterior MI & $(n=462)$ & $(n=429)$ & $(n=448)$ & $(n=449)$ & \\
\hline Age years (mean $\pm S D)$ & $62.5 \pm 11.7(n=462)$ & $63.5 \pm 12.2(n=429)$ & $63.1 \pm 12.0(n=448)$ & $63.4 \pm 12.1(n=449)$ & 0.488 \\
\hline Male gender & $338 / 462(73.2 \%)$ & $323 / 429(75.3 \%)$ & $318 / 448(71.0 \%)$ & $327 / 449(72.8 \%)$ & 0.556 \\
\hline Previous MI & $42 / 459(9.2 \%)$ & $41 / 427(9.6 \%)$ & $37 / 445(8.3 \%)$ & $64 / 448(14.3 \%)$ & 0.015 \\
\hline Previous CABG & $10 / 461(2.2 \%)$ & $14 / 428$ (3.3\%) & $16 / 447(3.6 \%)$ & $28 / 449(6.2 \%)$ & 0.012 \\
\hline Previous PCI & $44 / 461(9.5 \%)$ & $44 / 428(10.3 \%)$ & $41 / 447(9.2 \%)$ & $52 / 447(11.6 \%)$ & 0.628 \\
\hline Hypertension & $153 / 460(33.3 \%)$ & $137 / 427$ (32.1\%) & $169 / 445(38.0 \%)$ & $176 / 446(39.5 \%)$ & 0.061 \\
\hline DM & $52 / 461(11.3 \%)$ & $41 / 428(9.6 \%)$ & $53 / 444(11.9 \%)$ & $53 / 448(11.8 \%)$ & 0.669 \\
\hline Hypercholesterolemia & $122 / 460(26.5 \%)$ & $84 / 425$ (19.8\%) & $100 / 444(22.5 \%)$ & $111 / 446(24.9 \%)$ & 0.096 \\
\hline Smoking & $208 / 455$ (45.7\%) & $184 / 426(43.2 \%)$ & $210 / 440(47.7 \%)$ & $194 / 442$ (43.9\%) & 0.536 \\
\hline Killip class >1 & $437 / 462(94.6 \%)$ & $399 / 428$ (93.2\%) & $422 / 447$ (94.4\%) & $423 / 448$ (94.4\%) & 0.815 \\
\hline TIMI risk score & $2.17 \pm 1.94$ & $2.47 \pm 2.09$ & $2.45 \pm 2.10$ & $2.59 \pm 2.02$ & 0.008 \\
\hline \multirow[t]{2}{*}{$($ mean $\pm S D$, median $(I Q R))$} & $2.0(1.0-3.0)$ & $2.0(1.0-4.0)$ & $2.0(1.0-4.0)$ & $2.0(1.0-4.0)$ & \\
\hline & & & & & \\
\hline Field triage & $397 / 462(85.9 \%)$ & $317 / 429(73.9 \%)$ & $287 / 448(64.1 \%)$ & $198 / 449(44.1 \%)$ & $<0.001$ \\
\hline GPIIBIIIA blocker* & $131 / 393(33.3 \%)$ & $120 / 385(31.2 \%)$ & $131 / 383(34.2 \%)$ & $118 / 381$ (31.0\%) & 0.718 \\
\hline ST-segment deviation & $9.01 \pm 6.21$ & $8.50 \pm 6.48$ & $7.72 \pm 6.25$ & $6.34 \pm 5.63$ & $<0.001$ \\
\hline (diagnostic ECG) & $\begin{array}{l}8.0(5.0-11.0) \\
(n=297)\end{array}$ & $\begin{array}{l}7.0(4.0-11.0) \\
(n=279)\end{array}$ & $\begin{array}{l}6.0(4.0-10.0) \\
(n=311)\end{array}$ & $\begin{array}{l}5.0(3.0-9.0) \\
(\mathrm{n}=303)\end{array}$ & \\
\hline Multivessel disease & $247 / 462(53.5 \%)$ & $213 / 429(49.7 \%)$ & $234 / 447$ (52.3\%) & $249 / 447(55.7 \%)$ & 0.342 \\
\hline
\end{tabular}

${ }^{*}$ Administered in the acute phase.

$\mathrm{BI}$, balloon inflation; CABG, coronary artery bypass graft; DM, diabetes mellitus; GPIIBIIIA, glycoprotein IIBIIIA; MI, myocardial infarction; min, minutes; $\mathrm{PCl}$, percutaneous coronary intervention; TIMI, thrombolysis in myocardial infarction. 


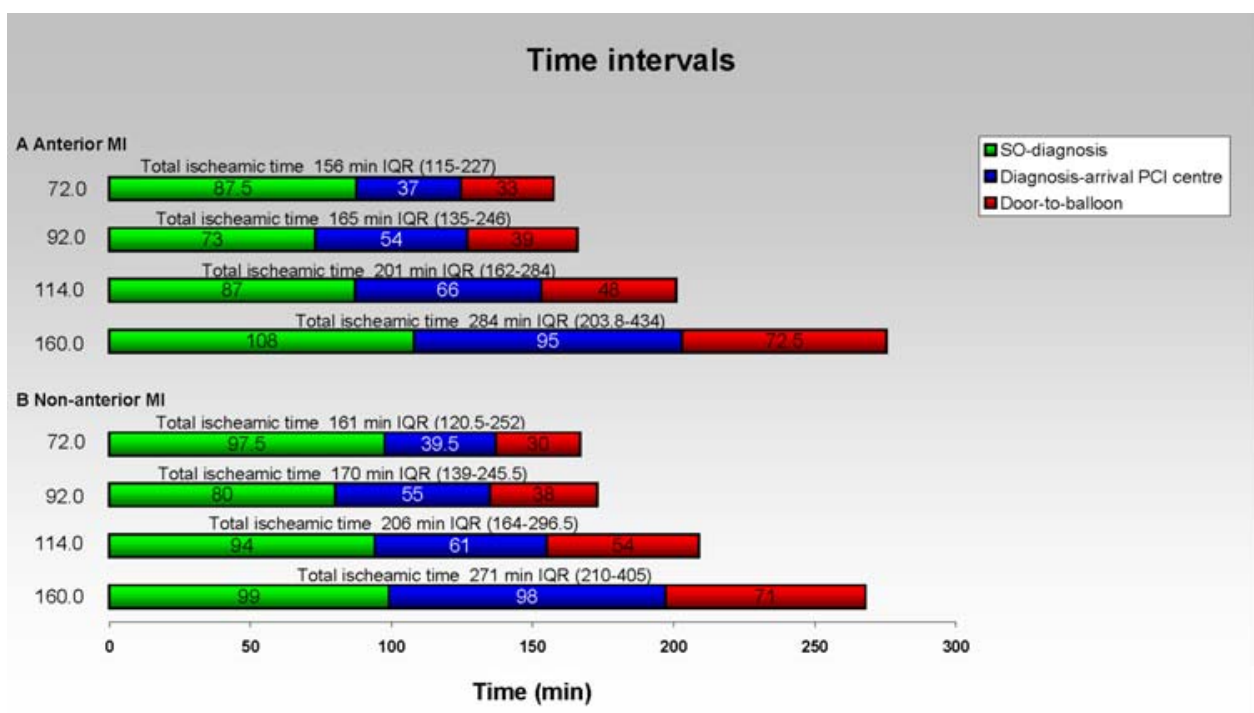

Figure 1 Time delays. The different time intervals are shown for patients with an anterior $\mathrm{Ml}(\mathrm{A})$ and patients with a non-anterior $\mathrm{MI}(\mathrm{B})$. MI, myocardial infarction; min, minutes; $\mathrm{PCl}$, percutaneous coronary intervention; $\mathrm{SO}$, symptom onset.

\section{Non-anterior MI}

The baseline characteristics are described in table 1 . Patients with prolonged system delay more often had a previous CABG, were less often diagnosed in the field and had less ST-deviation on the diagnostic ECG. There was a difference in previous MI and TIMI risk score among the quartiles of system delay. The culprit vessel in 1231 patients $(68.8 \%)$ was the right coronary artery and in 425 patients $(23.8 \%)$ it was the circumflex artery. The time intervals are illustrated in figure $1 \mathrm{~B}$. All time delays were significantly different between the quartiles of system delay. The median follow-up time was 5.2 (3.6-6.8) years. System delay was not associated with a large enzymatic infarct size (table 2). After Cox regression analysis, system delay was not associated with 30-day or with long-term mortality (figure $2 \mathrm{~B}$ ).

\section{DISCUSSION}

The present study is the first that assesses the effect of system delay on 30-day and on long-term mortality in patients with anterior and non-anterior MI separately. Interestingly, our results demonstrate that in patients with an anterior MI, system delay was significantly associated with 30-day and with long-term mortality. This effect was not apparent in patients with a non-anterior MI.

As demonstrated by Terkelsen et al, ${ }^{4}$ system delay seems to be the reasonable time delay to focus on in non-randomised studies, since confounding, selection bias, information bias and recall bias hamper the other currently discussed time delays. Another advantage of this time delay is that this delay can be optimised during the prehospital triage as well as during the inhospital triage.

Highly trained paramedics from several ambulance services transfer their patients to our high volume Isala
Hospital where over 2000 PCIs are performed yearly. Even though all prehospital and inhospital strategies and procedures are optimised, the variation between the quartiles of system delay differed between $72 \mathrm{~min}(\mathrm{Q} 1)$ vs $\geq 160 \mathrm{~min}(\mathrm{Q} 4)$. A possible explanation for the variations in system delay is the fact that very sick patients are also included in this study and these patients have longer delays. As demonstrated, in general, the TIMI risk score increases with system delay in both patient groups. Furthermore, D2B time increased with system delay despite an increase in patient delay (time from SO diagnosis). The latter might be explained by the fact that in patients with the longest system delay (Q4), a decrease in symptoms was more often demonstrated after arrival in the PCI hospital. Non-system reasons might also account for these findings. Examples of nonsystem delays include delays in providing procedure consent, difficult access, difficulty in crossing the culprit lesion and patients who have a cardiac arrest requiring intubation before PCI. ${ }^{11}$

An increase in 30-day and long-term mortality was demonstrated with system delay in patients with an anterior MI. We anticipated that in these patients also an increase in infarct size would be demonstrated since a large amount of myocardium is at risk in these patients; thus, anterior MI is a strong baseline determinant of infarct size. ${ }^{12}$ Furthermore, the association between system delay and infarct size has recently been demonstrated by Lønborg et $a l^{13}$ and Tödt $e t a l{ }^{14}$ In our population, however, only an increase in infarct size was demonstrated in patients with an anterior $\mathrm{MI}$ in the first three quartiles of system delay (Q1-Q3). An explanation for this result might be that patients with the longest system delays (Q4) had less severe and distinct symptoms, and less deviations on the ECG, which has consequently lead to a prolonged D2B time. In addition, 

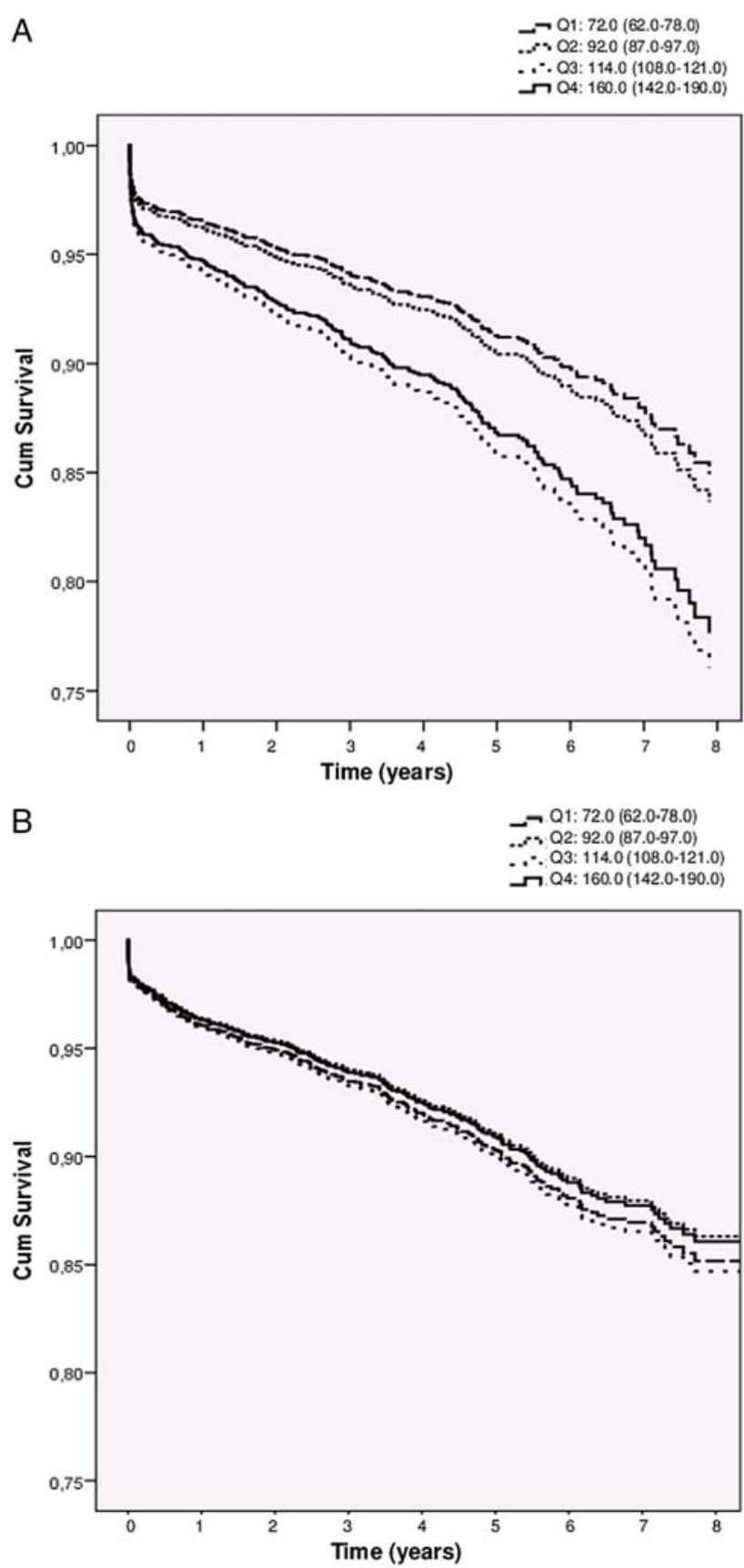

Figure 2 Mortality. Cox regression curves are shown for long-term mortality for patients with an anterior myocardial infarction (MI), (A) and patients with a non-anterior $\mathrm{MI}(\mathrm{B})$.

Lønborg et al and Tödt $e t$ al used MRI to assess the myocardial area at risk; this was not used in our study.

While prolonged system delay is associated with an increased mortality, especially in patients with an anterior MI, it is of the greatest importance to minimise system delay as much as possible. Therefore, currently several strategies have been developed to reduce system delay and other time delays. First, it is very important that the patients are triaged in the field by an ambulance and are transferred straight to the catheterisation laboratory of the PCI centre, bypassing the non-PCI

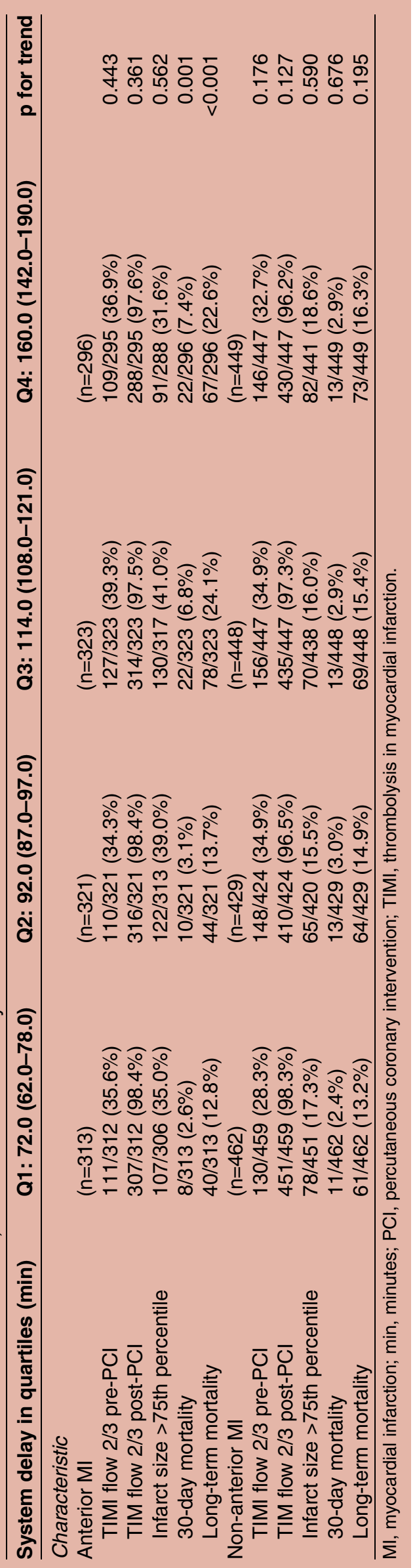


centres and the emergency department of the PCI centre. ${ }^{15}$ In our population, the benefit of this implemented strategy was obvious, that is, it was demonstrated that the amount of patients triaged in the field by an ambulance in Q1 was almost twice compared with the amount in Q4. Second, detailed identification of the time delays is essential so that an understanding can be gained. Third, collaborative discussions and feedback to staff involved in the care of patients with STEMI can make sure that the time delays can be optimised as much as possible. Points of discussion and feedback at present are (1) ECG recording by the highly trained paramedics in the ambulance, (2) central judgement of an ECG in the hospital, (3) timely preparation of catheterisation laboratory, and (4) prehospital and inhospital logistics. ${ }^{16}$

\section{Limitations}

First, the time of diagnosis was used together with the time of reperfusion therapy as a proxy for system delay. Information on the time of FMC was not available for all patients. However, a random sample of 94 cases revealed that in $83 \%$ of these patients, the difference between FMC (ie, EMS call) and diagnosis was $\leq 10 \mathrm{~min}$. Second, since the project was not randomised and dispersed over several years, the risk of unknown confounders exists. Third, the level of peak CK within $24 \mathrm{~h}$ was used as surrogate parameter for infarct size.

\section{CONCLUSIONS}

Prolonged system delay significantly increased short-term as well as long-term mortality in patients with an anterior MI. This effect was not demonstrated in patients with a non-anterior MI. Therefore, it is of the greatest importance to minimise system delay in patients who present with an anterior MI.

\section{Author affiliations}

${ }^{1}$ Diagram B.V., CRO, Zwolle, The Netherlands

${ }^{2}$ Department of Cardiology, Isala Hospital, Zwolle, The Netherlands

${ }^{3}$ Department of Cardiology, St Antonius Hospital, Nieuwegein,

The Netherlands

${ }^{4}$ Department of Cardiology, Radboudumc, Nijmegen, The Netherlands

Funding This research received no specific grant from any funding agency in the public, commercial or not-for-profit sectors.

Competing interests None.

Ethics approval The protocol was approved by the Local Institutional Review Board.

Provenance and peer review Not commissioned; externally peer reviewed.

Data sharing statement No additional data are available.
Open Access This is an Open Access article distributed in accordance with the Creative Commons Attribution Non Commercial (CC BY-NC 4.0) license, which permits others to distribute, remix, adapt, build upon this work noncommercially, and license their derivative works on different terms, provided the original work is properly cited and the use is non-commercial. See: http:// creativecommons.org/licenses/by-nc/4.0/

\section{REFERENCES}

1. Kushner FG, Hand M, Smith SC Jr, et al. 2009 Focused Updates: ACC/AHA Guidelines for the Management of Patients With ST-Elevation Myocardial Infarction (updating the 2004 Guideline and 2007 Focused Update) and ACC/AHA/SCAl Guidelines on Percutaneous Coronary Intervention (updating the 2005 Guideline and 2007 Focused Update): a report of the American College of Cardiology Foundation/American Heart Association Task Force on Practice Guidelines. Circulation 2009;120:2271-306.

2. Steg G, James SK, Atar D, et al., The task force on the management of ST-segment elevation acute myocardial infarction of the European Society of Cardiology (ESC). ESC Guidelines for the management of acute myocardial infarction in patients presenting with ST-segment elevation. Eur Heart J 2012;33:2569-619.

3. De Luca G, Suryapranata H, Ottervanger JP, et al. Time delay to treatment and mortality in primary angioplasty for acute myocardial infarction every minute of delay counts. Circulation 2004;109:1223-5.

4. Terkelsen CJ, Sørensen JT, Maeng M, et al. System delay and mortality among patients with STEMI treated with primary percutaneous coronary intervention. JAMA 2010;304:763-71.

5. Antman EM. Time is muscle: translation into practice. $\mathrm{J}$ Am Coll Cardiol 2008;52:1216-21.

6. Krumholz HM, Herrin J, Miller LE, et al. Improvement in door-to-balloon time in the United States, 2005 to 2010. Circulation 2011;30:1038-45.

7. Rathore SS, Curtis JP, Chen J, et al., National Cardiovascular Data Registry. Association of door-to balloon time and mortality in patients admitted to hospital with ST elevation myocardial infarction: national cohort study. BMJ 2009;338:b1807.

8. Wang TY, Nallamothu BK, Krumholz HM, et al. Association of door-in to door-out time with reperfusion delays and outcomes among patients transferred for primary percutaneous coronary intervention. JAMA 2011;305:2540-7.

9. Van 't Hof AWJ, Liem A, de Boer MJ, et al. Clinical value of 12-lead electrocardiogram after successful reperfusion therapy for acute myocardial infarction. Lancet 1997;350:615-19.

10. Nienhuis MB, Ottervanger JP, de Boer MJ, et al. Prognostic importance of creatine kinase and creatine kinase-MB after primary percutaneous coronary intervention for ST-elevation myocardial infarction. Am Heart J 2008;155:673-9.

11. Swaminathan RV, Wang TY, Kaltenbach LA, et al. Nonsystem reasons for delay in door-to-balloon time and associated in-hospital mortality: a report from the National Cardiovascular Data Registry. J Am Coll Cardiol 2013;61:1688-95.

12. Stone GW, Dixon SR, Grines CL, et al. Predictors of infarct size after primary coronary angioplasty in acute myocardial infarction from pooled analysis from four contemporary trials. Am J Cardiol 2007; 100:1370-5.

13. Lønborg J, Schoos MM, Kelbaek H, et al. Impact of system delay on infarct size, myocardial salvage index, and left ventricular function in patients with ST-segment elevation myocardial infarction. Am Heart J 2012;164:538-46.

14. Tödt T, Maret E, Alfredsson J, et al. Relationship between treatment delay and final infarct size in STEMI patients treated with abciximab and primary PCI. BMC Cardiovas Disord 2012;12:9.

15. Postma S, Dambrink JHE, de Boer MJ, et al. Pre-hospital triage in the ambulance reduces infarct size and improves outcome. Am Heart J 2011:161:276-82.

16. Tödt T, Thylén I, Alfredsson J, et al. Strategies to reduce time delays in patients with acute coronary heart disease treated with primary $\mathrm{PCl}$-the STOP WATCH study: a multistage action research project. BMJ Open 2013;3:e003493. 